\section{Unquiet Rest}

SIR,-Chauvinism in medical research is to be deplored, but your leading article on unquiet rest (23 September, p. 715) does less than justice to the pioneering British work of Masterton $^{1}$ on sleep patterns of junior medical staff. As early as 1965 he drew attention to both the lack of sleep obtained by busy residents on a surgical service and the effects this could have on the feelings they had about themselves and their work. The experiments of Friedman and his colleagues $^{2}$ referned to in your leading article now confirm objectively for medical performance what has been known for some time in other fields-namely, that in prolonged intellectual tasks ability declines with acute sleep lack. ${ }^{3}$ However, doctors are not yet sufficiently impressed with this to order their lives properly and, as Masterton showed, the pressure of external affairs in a hospital environment may be the overriding factor which produces the sleep lack state.

The lack of sleep in intensive care units has also been recognized since 1964, when Edgerton and $\mathrm{Kay}^{4}$ and Kornfield, Zimberg, and $\mathrm{Malm}^{5}$ first postulated that it might be of importance in the acute delirium-like states that can occur during incarceration in the intensive care environment. This hypothesis, which was extended by one of us (Dudley6) to include other problems of sensory barrage and deprivation, has proved somewhat too simplistic.

While by definition we can regard sleep lack as bad and from observation recognize that it may contribute to the patient's disturbed convalescence, its aetiological importance in delirium and its influence on the physiology of recovery require much further study.-We are, etc.,

H. A. F. DUdLEY M. W. JoHNS

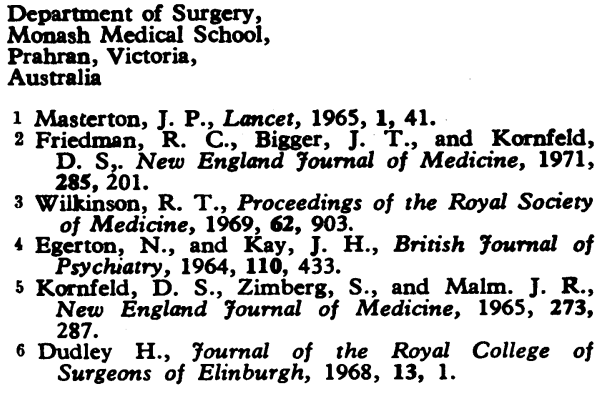

3 Wilkinson, R. T., Proceedings of the Royal Society of Medicine, 1969, 62, 903 .

Egerton, N., and Kay, J. H New England fournal of Medicine, 1965, 273, 287.

6 Dudley H., fournal of the Royal College of Surgeons of Elinburgh, 1968, 13, 1.

\section{Success of Adoption}

SIR,-Dr. J. E. G. Vincenzi (30 September, 831) states that 51 out of 1,000 children referred to a local authority child guidance clinic were adopted. This incidence of $5.1 \%$ is notably higher than that of $2.9 \%$ in a survey of about 1,600 referrals to a children's neuropsychiatric unit. ${ }^{1}$ Moreover, he gives no information on the proportion of these children adopted after the age of 6 months. Preadoptive trauma or lack of opportunity to form normal social attachments can lead to maladjustment, which cannot then be attributed to the child's adoptive status.

It is possible indeed that Growing $U p$ Adopted ${ }^{2}$ gives an over-optimistic view of adoption, and it is certain that the situation of the illegitimate child kept by his unmarried mother would be improved by better social support. However, Dr. Kellmer Pringle and her colleagues have been careful to point out, both in this report and elsewhere, ${ }^{3}$ that evidence from biased samples of the kind collected by psychiatrists is inherently suspect.-I am, etc.,

MichaEL HUMPHREY

St. Georges Hospital Medical School,

Humphrey, M., and Ounsted, C., British Fournal of Psychiatry, 1963, 109, 599.

Seglow, J., Kellmer-Pringle, M., and Wedge, P., Educational Research in England and Wales, 1972.

Pringle, M. L. K., Adoption-Facts and Fallacies. London, Longmans, 1967.

Sir,-Dr J. E. G. Vincenzi's warning (30 September, p. 831) against an overoptimistic view of the success rate in adoption is not borne out by our own national findings, ${ }^{1}$ even by the criterion of referral to child guidance clinics. There is no statistically significant difference between the adopted and the rest of the national cohort of children in the proportion who attended such clinics.

If some clinical studies find a higher proportion of adopted children among their referrals does this really warrant Dr. Vincenzi's assumption "that there is in these children a genetically determined maturational defect"? I would suggest that there are simpler explanations for any such phenomenon Perhaps I could mention just a few. Adopted parents have already had some dealings with the social and medical services in connextion with their adopted child and will usually be conscious of any preplacement handicaps, so may well be more ready to seek specialist advice. Because the myth of "bad blood" and of the adverse effects of poor heredity is so prevalent adoptive parents may be more prone than parents generally to think they can see signs of instability. Also adopters may be less reluctant to admit to behaviour difficulties in their adopted children, feeling that "heredity" rather than they themselves may be responsible. And a similar process of rationalization may make teachers, doctors, and social workers more ready to refer the adopted child for psychiatric advice.

Thus it seems to me that whatever arguments there might be for or against adoption it is unwise to cite the referral rate to psychiatric services as a "warning." All studies of adopted children have shown that the kind of home the parents provide and the kind of care they bestow are the most important preconditions for a satisfactory outcome for all concerned.- I am, etc.

London $\mathbf{W} .1$

Mia Kellmer Pringle

1 Seglow, J., Kellmer Pringle, $M$. , and Wedge, P., Educational Research in England and $W$ ales, 1972.

\section{Scrotal Cancer Continues}

SIR,-Your leading article on scrotal cancer (7 October, p. 3) stands in need of correction on one point. Percivall Pott died in 1788, so it was not he who described the case of epithelioma on the wrist of a gardener in 1808. This case was added in a footnote to Pott's original description of cancer scroti by James Earle, who edited the posthumous editions of Pott's book of surgery.1 It was one of two cases which Earle mentioned in the note, both designed to illustrate the dangerous nature of soot. In addition to the account of the gardener Earle recounts a case of scrotal cancer in a man who was not a sweep but who had lodged for some years in a sweep's house in the room where the bags of soot were stored. He developed signs of the disease only after he had moved out into more pleasant lodgings.

Earle's reason for adding these cases was, he said, because "Mr. Pott seemed to suppose that this species of cancer was peculiar to chimney-sweepers; but I have strong grounds for thinking that he was mistaken in that idea." And so he was.-I am, etc.,

H. A. WALDRON

Medical School,

University of Birmingham

1 The Chirurgical Works of Percival Pott, a new edition to which are added occasional notes and observations by Sir James Earle, Vol. 3, p. 182 London, J. Johnson, 1808.

\section{Malaria in the U.K}

SIR,-I refer to the most unsatisfactory comments made by your correspondents from the Public Health Laboratory Service on the subject of Dr. M. J. Colbourne's letter (14 October, p. 112).

The original statement (9 September, p. 652) baldly states that "so far as is known there are no drug-resistant stains [P. falciparum] in Africa." This is an obviously incorrect statement so why not admit it and explain that "when discussing resistance we were referring to treatment and not prophylaxis"? Dr. Colbourne was perfectly justified in drawing attention to this erroneous and even misleading statement which could well have led to wrong advice being given about malarial prophylactic drugs in Africa.

The report by Sagnat and others ${ }^{1}$ refers to a series of $\mathbf{4 5}$ comatose children suffering from malaria and admitted to a paediatric hospital in Brazzaville. It can hardly be accepted as epidemiological evidence on which to base a "figure of $35 \%$ for the death rate in $P$. falciparum infections in West Africa"-in my experience this is far too high.-I am, etc. Wellcome Foundation Ltd.,
London N.W.1

C. V. FoLI Sagnat, H., Morineaud, J. P., Revil, H., Thomas,
J., and Masart, Y., Médecine Tropicale, 1967,
27, 606.

Pigmentation in Megaloblastic Anaemia

SIR,-Hyperpigmentation of the skin of the palms, over the interphalangeal joints and terminal phalanges of the soles of the feet, and of the buccal mucous membranes has been described in vitamin $B_{12}$-deficient Indian adults and infants ${ }^{1}$ and Nigerian adults. ${ }^{2}$ Less pronounced but similar changes were reported in folate-deficient South African women in the postnatal period, ${ }^{3}$ but in a previous note ${ }^{4}$ it was denied that hyperpigmentation was ever seen in folatedeficient pregnant Nigerians. It has been suggested that this is a physical sign specific to vitamin $B_{12}$ deficiency. ${ }^{1}$ We wish to report a Nigerian woman with striking hyperpigmentation of the soles and palms (Figure), though not of the buccal mucosa, associated with megaloblastic anaemia and folate deficiency. 